\title{
ENCLOSURE OF AIR DURING METAMORPHOSIS OF DRY FIRN TO ICE
}

\author{
by
}

\author{
B. Stauffer, J. Schwander AND H. Oeschger
}

Physics Institute, University of Bern, Switzerland

\section{ABSTRACT}

If cold firn has reached a density of about 0.55 $\mathrm{Mg} \mathrm{m} \mathrm{m}^{-3}$, further densification occurs by a sintering process which increases the contact surface between the firn grains. The pore volume is decreasing continuously but the firn remains permeable to air up to a density of $0.82 \mathrm{Mg} \mathrm{m}^{-3}$. At about this density the remaining air in the pore volume is closed off in isolated bubbles. We are interested in the age and the age distribution of the air enclosed in bubbles relative to the age of the surrounding ice, and are investigating the development of the pore volume in firn.

A newly constructed measuring device allows the field measurement of the amount of air which is already enclosed in bubbles of firn samples. Measurements have been made during summer 1983 in Greenland and during winter 1983/84 at the South Pole. The results are discussed and compared with results obtained with a simplified statistical sintering model, using some results of percolation theory.

\section{INTRODUCTION}

The presence of bubbles is one of the typical properties of natural ice. Air in bubbles of ice which was formed by sintering of dry firn has essentially the same composition as that of the atmosphere at the time of bubble formation. The analysis of dated ice samples therfore allows the investigation of the history of atmospheric composition (Delmas and others 1980; Berner and others 1980). The age of the enclosed air is, however, not the same as that of the surrounding ice since air bubbles become isolated from the atmosphere during the transition from firn to ice, occurring typically 100 to 3000 years af ter snow deposition. The time needed to transform freshly deposited snow into ice depends mainly on firn temperature and snow accumulation rate. The mean age difference between ice and enclosed air, as well as the width of the age distribution for a given sample, depend on the enclosure process and on the age of the atmospheric air in the permeable firn. The enclosure process, investigated by measurements on firn samples and by computer simulations with a simplified sintering model, are discussed in this paper. Concerning the age in the permeable firn, we have some evidence that the air is well mixed with the atmosphere to a depth of several meters above the transition zone (Loosli 1983; Stauffer and others 1981). More measurements are needed to decide whether the air is well mixed down to the transition zone or not.

To investigate the enclosure process the fraction of air, which is already isolated from the atmosphere, has to be measured as a function of depth.

\section{EXPERIMENTAL PROCEDURE}

A widely applied method to measure the isolated fraction of air in a firn sample is to remove the air in the open pore space, melt the sample afterwards and measure the amount of gas extracted during melting of the sample (Langway 1958; Raynaud and Lebel 1979). Two methods have been used to remove the air from the open pore space: by evacuating the container with the firn sample or by immersing the sample slowly in a liquid which displaces the air in the open pore volume.
The two methods do not give the same results. By evacuating the container containing the firn sample, there is some risk of breaking isolated but still fragile bubbles due to the high pressure difference between bubbles and the evacuated open pore space. By immersing the sample, air from open but dead-ended channels may not be removed.

To avoid these problems, we applied a classical method based on the law of Boyle-Mariotte for idea gases. The measuring device is shown schematically in Figure 1. The three volumes $\mathrm{V}_{1}\left(110.3 \mathrm{~cm}^{3}\right), \mathrm{V}_{2}(110.2$ $\mathrm{cm}^{3}$ ), and $\mathrm{V}_{3}\left(12.7 \mathrm{~cm}^{3}\right)$ have been machined into one massive aluminium block to keep all three volumes at the same temperature.

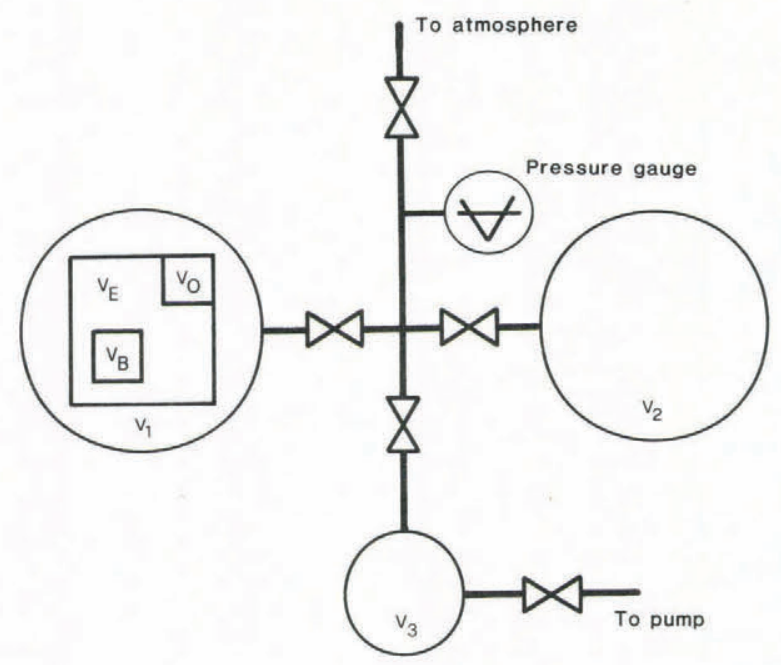

Fig.1. Schematic arrangement of system to measure the enclosed bubble volume of firn and ice samples.

The firn samples are cut on a small turntable to a cylindrical shape. The bulk volume about $35 \mathrm{~cm}^{3}$ is determined by measuring length and diameter of the cylinder, accuracy $0.1 \%$. The weight is measured with an absolute accuracy of $0.02 \mathrm{~g}$. The ice volume $V_{E}$ is calculated using a density of $0.919 \mathrm{Mg} \mathrm{m}^{-3}$ for pure ice at $-25^{\circ} \mathrm{C}$

For the measurement, volume $V_{1}$ containing the firn sample is disconnected from the atmosphere and connected to $\mathrm{V}_{3}$ which was evacuated previously. The pressure drop $\Delta \mathrm{p}_{1}$ due to expansion is measured. Assuming an isothermal process, the bubble volume $V_{B}$ can be calculated:

$$
\begin{aligned}
& \mathrm{V}_{\mathrm{B}}=\mathrm{V}_{\mathrm{A}}-\mathrm{V}_{\mathrm{E}} \\
& \left(\mathrm{p}_{\mathrm{A}}-\Delta \mathrm{p}_{1}\right)\left(\mathrm{V}_{1}-\mathrm{V}_{\mathrm{A}}+\mathrm{V}_{3}\right)=\left(\mathrm{V}_{1}-\mathrm{V}_{\mathrm{A}}\right) \mathrm{p}_{\mathrm{A}}
\end{aligned}
$$

where: $\mathrm{p}_{\mathrm{A}}=$ atmospheric pressure

$$
\mathrm{V}_{\mathrm{B}}=\text { bubble volume }
$$


By measuring in a second step the pressure drop $\Delta \mathrm{p}_{2}$ by connecting the calibrated volume $V_{2}$ at atmospheric pressure to $\mathrm{V}_{3}$ which was evacuated again previously, we can replace $p_{A}$ :

$$
\mathrm{V}_{\mathrm{A}}=\mathrm{V}_{1}+\mathrm{V}_{3}-\frac{\Delta \mathrm{p}_{2}}{\Delta \mathrm{p}_{1}}\left(\mathrm{~V}_{2}+\mathrm{V}_{3}\right)
$$

Thus $\Delta \mathrm{p}_{2}$, a pressure change of the same order as $\Delta \mathrm{p}_{1}$, can be measured with the same instrument, instead of the atmospheric pressure, assuming that $\mathrm{p}_{\mathrm{A}}$ remains constant during the two measurements.

The pressure drop $\Delta p_{1}$ is of the order of $5000 \mathrm{~Pa}$ $(0.05$ bar $)$. This small pressure change should exclude any danger of breaking fragile isolated bubbles.

The method has several possible error sources which are discussed in detail by Schwander (1984). An important correction involves the water vapour pressure. Equation 2 has to be corrected to:

$$
\begin{aligned}
\mathrm{V}_{\mathrm{A}} & =\mathrm{V}_{1}+\mathrm{V}_{3}-\frac{\Delta \mathrm{p}_{2}}{\Delta \mathrm{p}_{1}}\left(\mathrm{~V}_{2}+\mathrm{V}_{3}\right) \\
& +\mathrm{p}_{\mathrm{w}} \mathrm{V}_{3} \cdot\left[\frac{1}{\Delta \mathrm{p}_{1}}-\frac{\mathrm{V}_{3}}{\Delta \mathrm{p}_{2}\left(\mathrm{~V}_{2}+\mathrm{V}_{3}\right)}\right]
\end{aligned}
$$

where: $p_{w}=$ water vapour pressure.

A correction due to adiabatic cooling during expansion can be neglected, if the pressure readings are done $20 \mathrm{~s}$ after the expansion. The influence of the Joule-Thomson effect as well as the deviation of air from an ideal gas (Van der Vaals correction) can also be neglected.

The experimental method was tested with bubble free ice. The accuracy of the bulk density and bubble volume measurements are $\pm 0.002 \mathrm{Mg} \mathrm{m}^{-3}$ respectively \pm $2 \mathrm{~cm}^{3} \mathrm{~kg}^{-1}$.

\section{RESULTS}

Measurements were done on a firn/ice core from Dye 3 (South Greenland, $65^{\circ} 11^{\prime} \mathrm{N}, 43^{\circ} 50^{\prime} \mathrm{W}$ ) and on a core from Siple Station (West Antarctica, $75^{\circ} 55^{\prime} \mathrm{S}$, $\left.83^{\circ} 55^{\prime} \mathrm{W}\right)$. The measurements on the core from Dye 3 were done in summer 1983, the measurements on the core from Siple Station with improved equipment and under more favorable conditions in December 1983 in a snow trench at the South Pole. Results from the Siple core will be reported. The mean annual air temperature for this site is $-24^{\circ} \mathrm{C}$ which minimizes the risk of an influence of the sintering process by meltwater. Only one melt-layer of $10 \mathrm{~mm}$ thickness was observed in the entire firn core. The high annual accumulation of about $0.5 \mathrm{Mg} \mathrm{m} \mathrm{m}^{-2}$ allows the study of seasonal effects. Counting the seasonal variations of the electrical conductivity of the ice core allows also a dating of the core over the last 200 years with an accuracy of \pm 2 years (Schwander and Stauffer 1984).

Density and bubble volume of a total of 257 samples from 10 to $91 \mathrm{~m}$ depth below the 1982 snow surface were determined. Each point in Figure 2 represents the average of 10 measurements done on samples from a $1 \mathrm{~m}$ long ice core. Samples have been taken every $10 \mathrm{~m}$ to a depth of $60 \mathrm{~m}$ below surface. From 64 to $81 \mathrm{~m} 182$ samples of $0.1 \mathrm{~m}$ length have been measured. The enclosure process mainly takes place in a depth interval between $64 \mathrm{~m}$ and $76 \mathrm{~m}$. Only $10 \%$ of the final bubble volume is enclosed above $64 \mathrm{~m}$ and only $10 \%$ below $76 \mathrm{~m}$. This depth interval is characteristic for Siple Station only. There is a clear dependence between density and bubble volume which is shown in Figure 3 .

Figure 4 shows all results of a small section of the Siple core. The bubble volume, as well as the bulk density, shows seasonal variations demonstrated by the comparison with electrical conductivity measurements. The summer layers at this depth are characterized by low density and low isolated bubble volume.
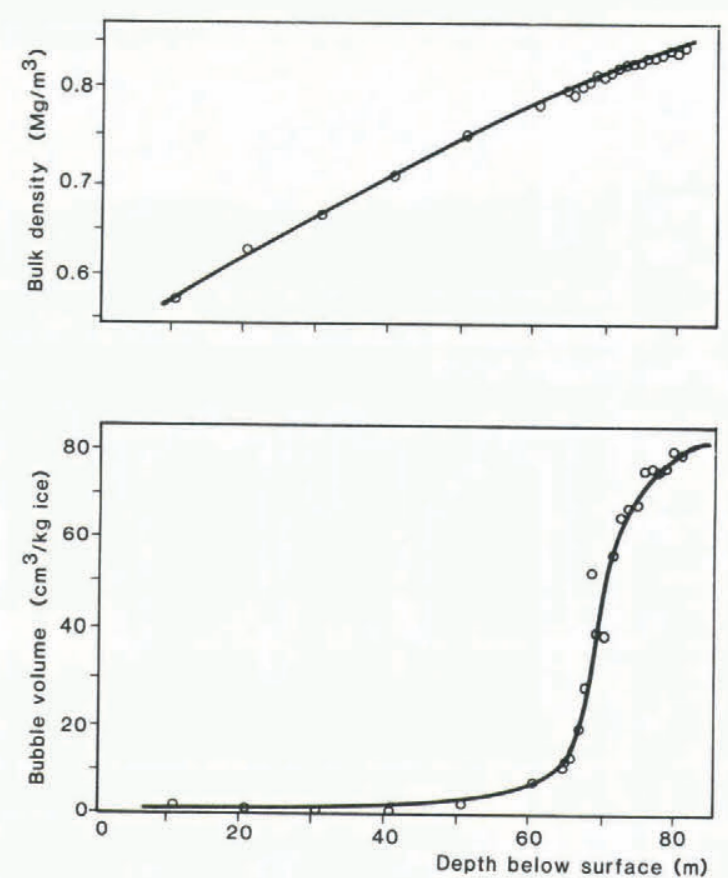

Fig.2. Bulk density and bubble volume versus depth at Siple Station. Each point represents a one meter average.

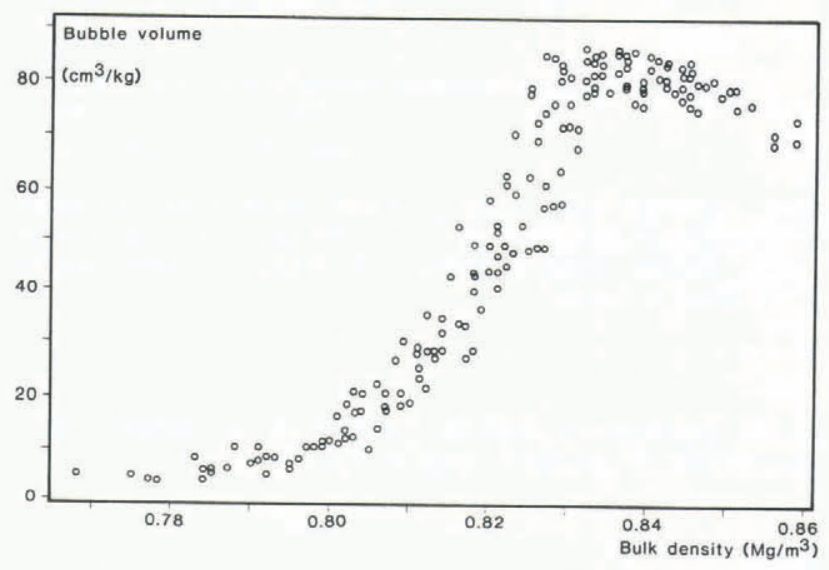

Fig.3. Bubble volume versus bulk density for all samples from Siple Station between $60 \mathrm{~m}$ and $81 \mathrm{~m}$ depth below surface.

\section{DISCUSSION OF RESULTS}

Bubble close-off occurs at different sites in different depth depending on accumulation rate and temperature, but at about the same mean density (Raynaud and Lebel 1979). Based on this observation, on measurements made on firn samples from North Central (Greenland) (Stauffer and others 1981), and due to results we obtained from the firn core from Dye 3 , we make the hypothesis that the relation between isolated bubble volume and density, shown in Figure 3 , is valid for all sites where ice is formed by sintering of dry firn. The isolated bubble volume is, however, not identical with the enclosed amount of gas since the pressure in bubbles is not uniform.

The pressure in the bubbles starts to increase above atmospheric as soon as the bubbles are closed-off since the hydrostatic pressure of the surrounding ice is higher. At Siple Station (elevation $1054 \mathrm{~m}$ a.s.l.) we expect a mean air content of the ice of $120 \mathrm{~cm}^{3}$ (STP) $\mathrm{kg}^{-1}$ (Raynaud and Lebel 1979). At the end of the pore close-off, the measured bubble volume is only $80 \mathrm{~cm}^{3}$ $\mathrm{kg}^{-1}$. The mean pressure in the bubbles therefore has to be about $140 \mathrm{kPa}$ (1.4 bar). The pressure, not uniform, is larger in bubbles isolated at shallow depth compared 

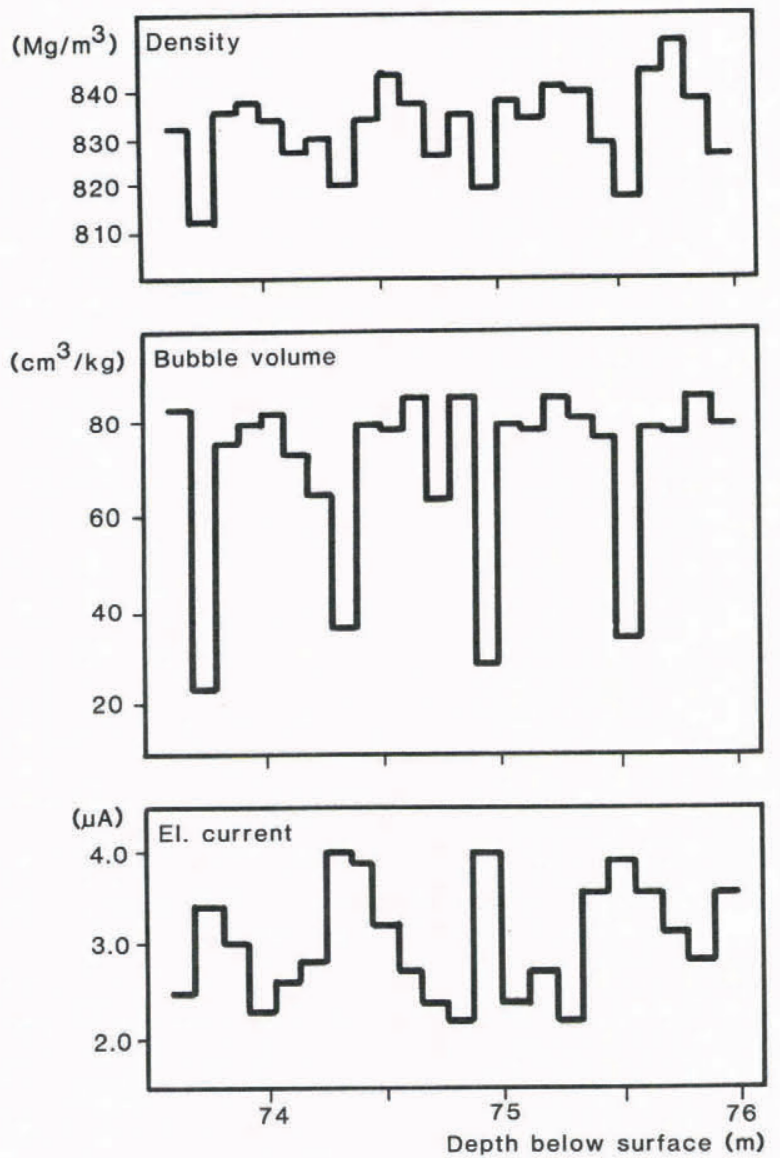

Fig.4. Detailed bulk density, bubble volume and electrical conductivity measurements for a section of firn core from Siple Station. High electrical conductivity is characteristic for summer layers.

to the pressure in bubbles enclosed at a deeper depth. The volume of isolated bubbles $V_{B}$ is given by:

$$
\mathrm{V}_{B}\left(\mathrm{~h}_{2}\right)=\int_{0}^{\mathrm{h}_{2}} \mathrm{~V}\left(\mathrm{~h}_{1}\right) \cdot \mathrm{B}\left(\mathrm{h}_{1}, \mathrm{~h}_{2}\right) \cdot d \mathrm{~h}_{1}
$$

where: $V\left(h_{1}\right) d h_{1}=$ geometrical volume which is enclosed in depth interval $\mathrm{dh}_{1}$.

$B\left(h_{1}, h_{2}\right)$ is the factor by which the volume enclosed at $h_{1}$ has been compressed when reaching the depth $h_{2}$. Schwander (1984) suggests an approximate solution, using a step function:

$$
\mathrm{V}_{\mathrm{B}}\left(\mathrm{h}_{2}\right)=\mathrm{B}\left(\mathrm{h}_{1}, \mathrm{~h}_{2}\right) \cdot \mathrm{V}\left(\mathrm{h}_{1}\right)
$$

where $V_{B}\left(h_{2}\right)$ and $V\left(h_{1}\right)$ are vectors, and $B\left(h_{1}, h_{2}\right)$ is a matrix. The elements of the matrix may be calculated if the compression of a bubble as a function of hydrostatic pressure and time is known. The compression formulae given by Wilkinson and Ashby (1975) have been used. The results depend on the shape of the bubbles. It is assumed that the shape is cylindrical after close of $f$ and becomes spherical after a few meters. Figure 5 shows the calculated enclosed amount of gas in function of depth. The depth interval needed to transform bubbles from a cylindrical into a spherical shape is the parameter. With $16 \mathrm{~m}$ depth interval the calculated amount of gas is $126 \mathrm{~cm}^{3} \mathrm{~kg}^{-1}$ (corresponding to about $120 \mathrm{~cm}^{3}$ (STP) $\mathrm{kg}^{-1}$ ).

At $75 \mathrm{~m}$ depth summer layers are characterized by low density and low isolated bubble volume. Summer layers are, however, characterized by high air content

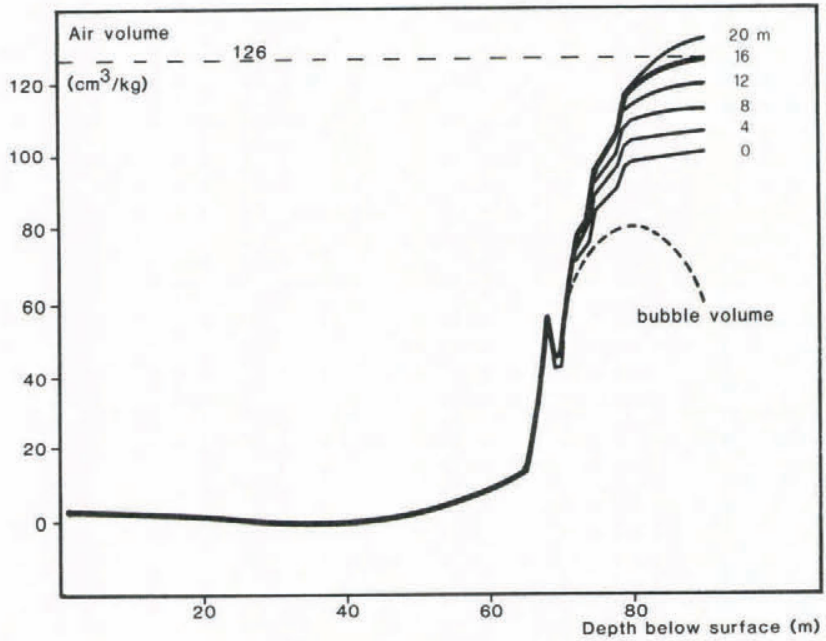

Fig.5. Calculated bubble volume (STP) assuming a mean atmospheric pressure of 867 mbar. The parameter is the mean depth interval needed to transform cylindric to spheric bubbles.

compared to winter layers (Berner and others 1979); Raynaud and Lebel 1979). We assume that impermeable winter layers are sealing permeable summer layers beneath with lower density and therefore higher porosity, against the atmosphere. The air in the summer layer cannot escape anymore and leads to a higher air content. An impermeable layer has a limited horizontal extension. The sealing effect is therefore only effective if the permeability of the layer beneath is reduced, still permeable over a distance typical for the layer thickness but impermeable over much larger horizontal distances.

\section{COMPARISON WITH SIMPLIFIED STATISTICAL SINTERING MODEL}

The sintering process of a powder compound is generally divided into three stages (Geguzin 1973). Contact areas between single grains are small in stage 1 , while stage 2 is characterized by contact areas of the order of the cross section of the grains. Stage 3 is characterized by isolated bubbles. If density of firn is measured as a function of depth discontinuities are observed at densities of $0.55 \mathrm{Mg} \mathrm{m}^{-3}$ and $0.82 \mathrm{Mg} \mathrm{m}^{-3}$ (Anderson and Benson 1963). Maeno observed discontinuities of a few parameters at a density of 0.73 $\mathrm{Mg} \mathrm{m}{ }^{-3}$ (Maeno 1978). Firn grains of irregular shape and size are packed at random and have small contact areas at a density of $0.55 \mathrm{Mg} \mathrm{m}^{-3}$. Spheres of uniform size packed analogic to a body centered lattice are considered to be a useful approximation to the irregular packing of firn grains. If the grains sinter together by enlarging the circular contact areas, their shape will change slowly from spheric to the shape of a tetrakaidekaeder (truncated octaeder). This shape is a good approximation of many shapes found in nature (Desch 1919). If the circular contact areas grow simultaneously, all channels connecting air pockets in the corners where four tetrakaidekaeders meet, will close simultaneously and isolate the remaining air in each corner (Stauffer 1981). Beere (1973) has calculated the remaining porosity approximately by assuming that the surface energy is the driving force. Observations of firn samples from a depth interval where bubbles are enclosed show that they are often present in small clusters with channels connecting them and that there are only one to two bubbles per grain (single crystal) (Gow 1968) instead of six as Beere's model would suggest.

Coble (19161) uses the same regular packing of grains but approximates the shape of the pore volume by cylindric channels going along with each boundary where three tetrakaidekaeder meet. A decrease of the porosity (increase of density) may occur by a decrease of the cylinder radius or by the closure of single 
channels. Maeno suggests that the decrease of the diameter of the cylinders is dominant in sintering of firn until a density of $0.73 \mathrm{Mg} \mathrm{m}^{-3}$ is reached, and that further densification occurs by eliminating whole channels.

We assume for the following comparison that firn with a density of $0.73 \mathrm{Mg} \mathrm{m}^{-3}$ consists of a regular arrangement of regular tetrakaiderkaeders of uniform size and that the porosity consists of channels of uniform size and that there is such a channel at each boundary where three grains meet. The decreasing porosity accompanying a further densification shall be proportional to the decreasing number of channels. The idea is illustrated in Figure 6 with a two-dimensional hexagonal lattice. The bonds represent the air filled channels. The isolation of single bonds or clusters of bonds is a problem of bond percolation (Essam 1980). The probability $P(p)$ that a certain bond is connected by a string of bonds with the surface is a uniformly increasing function of the probability $p$ for the existence of single bonds. For a large number of bonds the probability $p$ is identical with the remaining fraction of bonds and therefore proportional to porosity. For an infinite sample the probability $P(b)$ that $a$ bond is connected to an infinite cluster is zero if $p$ is below the critical probability $\mathrm{p}_{\mathrm{c}}$. All bonds are therefore isolated in an infinite sample if $p$ is below $p_{c}$, this corresponds with the transition from firn to ice. The critical probability for the two-dimensional hexagonal structure is $p_{c}=0.653$ (Hammersley and Welsh 1980). for three-dimensional structures we found only the critical probability for the face centered cubic lattice in literature (Essam 1980): $p_{c}=0.1185$. for the structure given by the edges of the tetrakaiderkaeders we estimate, based on computer simulations, that the critical probability is about $\mathrm{p}_{\mathrm{c}}=0.42$.

The probability $\mathrm{p}=1$ corresponds to $100 \%$ channels between the tetrakaiderkaeders and therefore to a density of $0.73 \mathrm{Mg} \mathrm{m}^{-3}$ according to Maeno (1978). The porosity $n$ resp. $\Pi^{\prime}$ is related to density:

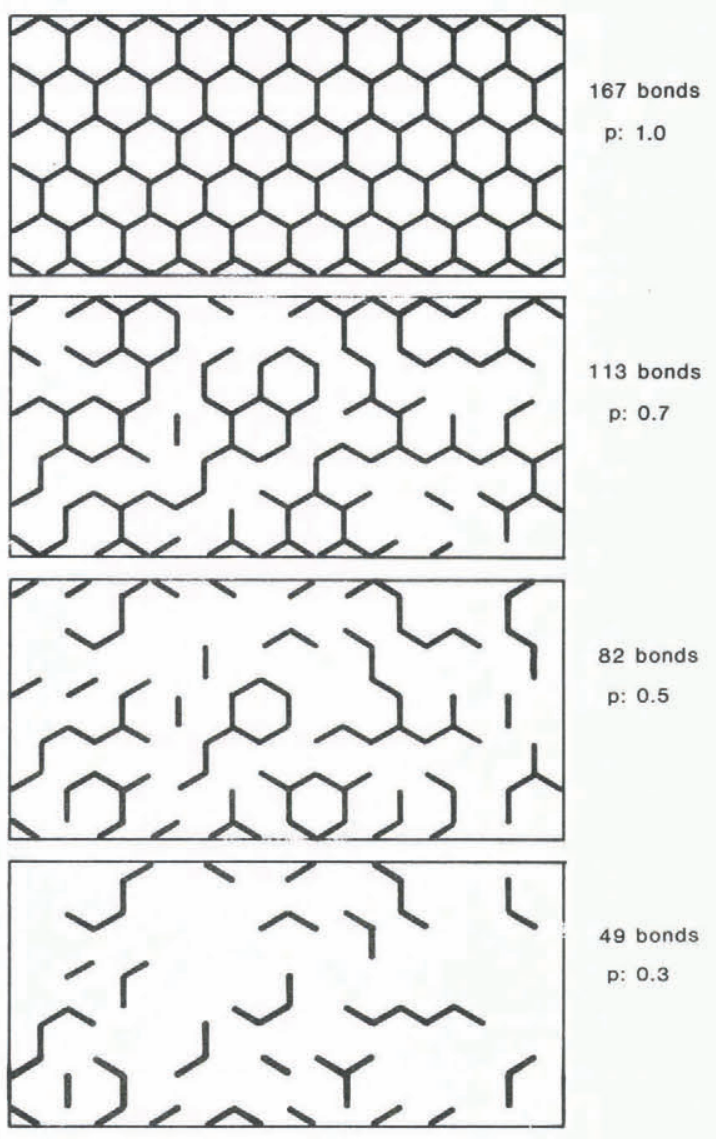

Fig.6. Two-dimensinal hexagonal lattice. Bonds have been eliminated according to random numbers.

$$
\Pi=\left(\begin{array}{ll}
\left.\rho_{i}-\rho_{f}\right) / \rho_{i} & \Pi^{\prime}=\left(\rho_{i}-\rho_{f}\right) /\left(\rho_{i} \cdot \rho_{f}\right)
\end{array}\right.
$$

where: $\rho_{\mathrm{i}}=$ density of pure ice $\left(0.919 \mathrm{Mg} \mathrm{m}^{-3}\right)$

$\rho_{f}=$ bulk density of firn

Porosity $\Pi$ is $0.20 \mathrm{~m}^{3} / \mathrm{m}^{3}$ for $\rho_{\mathrm{f}}=0.73 \mathrm{Mg} \mathrm{m}^{-3}$. If the critical percolation probability for the structure in question is $p_{c}=0.42$, only $42 \%$ of the channels are still existing at the transition from firn to ice. This corresponds to a porosity of $\Pi=0.084 \mathrm{~m}^{3} / \mathrm{m}^{3}$ and a firn density of $0.840 \mathrm{Mg} \mathrm{m}^{-3}$, which is in good agreement with the observations.

For finite samples all bonds connected to the surface of the sample contribute to the open pore volume, also if they would belong in the infinite sample to an isolated cluster of bonds. The porosity of a sample is given by the total number of existing bonds per volume, the bubble volume by the number of bonds which are not connected with the sample surface. The enclosure of bubbles can be simulated. More and more bonds of the three-dimensional structure are eliminated according to random numbers generated by the computer. The total number of bonds (corresponding to porosity) and the number of bonds not connected with the surface (corresponding to bubble volume) are counted in intervals.

The results of a computer simulation are shown in Figure 7. We started with $324,1500,4116$ and 8748 bonds for the structure corresponding to a firn density of $0.73 \mathrm{Mg} \mathrm{m}^{-3}$. A firn sample of $35 \mathrm{~cm}^{3}$ at this density has about 30000 channels. Channels in ice are not

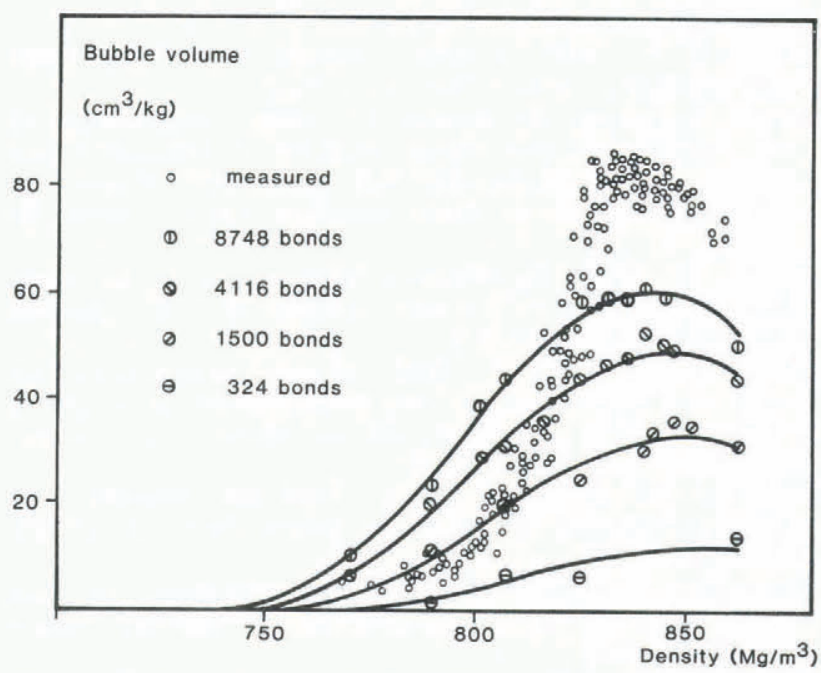

Fig.7. Enclosure of bubbles. Comparison of measured values with results from a simplified statistical model. The indicated number of bonds corresponds with the number of channels in a sample with the density $0.73 \mathrm{Mg} \mathrm{m}^{-3}$.

eliminated any more as soon as they are enclosed, but they are shrinking, leading to a decrease of the bubble volume after completed close off. The computer simulation is not taking into account any shrinking of bonds, but isolated bonds are also allowed to be eliminated, which causes about the same effect.

The results of the simulation show the same trend as the measured values. The increase and absolute value of the bubble volume depends on sample size, respectively on the number of bonds. The model is in agreement with the observation that there are about two bubbles (bonds) per single crystal (tetrakaiderkaeder) at bubble close off, and that bubbles are of ten collected to small clusters.

\section{ACKNOWLEDGEMENTS}

This work has been supported by the Swiss National Science Foundation, by the DPP of US 
National Science Foundation and the University of Bern. The ice core at Siple Station was drilled by the Polar Ice Coring Office, Nebraska.

\section{REFERENCES}

Anderson D L, Benson C S 1963 Thedensification and diagenesis of snow. Ice and Snow, MIT Press, Massachusetts, USA: $391-411$

Beere W 1973 Energy considerations of intergranular pores and their relevance to gas release in fuels. Physical Metallurgy of Reactor Fuel Elements. Metals Society, London

Berner W, Stauffer B, Oeschger H 1979 Past, atmospheric composition and climate, gas parameters measured on ice cores. Nature 275(5683): 53-55

Coble R L 1961 Sintering crystalline solids. Journal of Applied Physics 32: 787-799

Desch C H 1919 The solidification of metals from the liquid state. Journal of Instrumental Metallurgy 22: 241-276

Delmas R J, Ascencio J M, Legrand M 1980 Polar ice evidence that atmospheric $\mathrm{CO}_{2} 20000$ years $\mathrm{BP}$ was $50 \%$ of present. Nature 284: $155-157$

Essam J W 1980 Percolation theory. Reports on Progress in Physics 43: 833-912

Geguzin J E 1973 Physik des Sinterns. VEB Deutscher Verlag fur Grundstoffindustrie, Leipzig

Gow A J 1968 Bubbles and bubble pressure in Antarctic glacier ice. Journal of Glaciology 7(50): $167-182$

Hammersley J M, Welsh D J A 1980 Percolation theory and its ramifications. Contemporary Physics 21(6): 593-605

Langway C C 1958 Physics of the movement of the ice. IAHS Publication 47: 336-349

Loosli H H 1983 A dating method with ${ }^{39}$ Ar. Earth and Planetary Science Letters 63: 51-62

Maeno N, Narita M, Araoka K 1978 Measurements of air permeability and elastic modulus of snow and firn drilled at Mizuho Station East Antarctica. Memoirs of National Institute of Polar Research Special Issue 10: 62-76

Maeno N 1982 Densification rates of snow at polar glaciers. Memoirs of National Institute of Polar Research Special Issue 24: 204-211

Maeno N, Ebinuma T 1983 Pressure sintering of ice and its implication to the densification of snow at polar glaciers and ice sheets. Journal of Physical Chemistry 87(21): 4103-4110

Raynaud D, Lebel B 1979 Total gas content and surface elevation of polar ice sheets. Nature 281(5729): 289-291

Schwander J, Stauffer B 1985 Age difference between polar ice and the air trapped in its bubbles. Nature 315(6014): 45-47

Schwander J 1984 Lufteinschluss im Eis von Groenland und der Antarktis. ( $\mathrm{PhD}$ thesis, University of Bern 1984)

Stauffer B, Berner W, Oeschger H, Schwander J 1981 Atmospheric $\mathrm{CO}_{2}$ history from ice core studies. Zeitschrift fur Gletscherkunde und Glazialgeologie 17(1): 1-16

Stauffer B 1981 Mechanismen des Lufteinschlusses in natuerlichem Eis. Zeitschrift fur Gletscherkunde und Glazialgeologie 17(1): 17-56

Wilkinson D S, Ashby M F 1975 Pressure sintering by power law creep. Acta Metallurgica 23: 1277-1285 